speckle-tracking echocardiography for quantitative assessment of global left ventricular function: a comparative study to three-dimensional echocardiography. J Am Soc Echocardiogr, 2014. 27(3): p. 285-91.

8. Streeter Jr, D.D., et al., Fiber orientation in the canine left ventricle during diastole and systole.
Circulation research, 1969. 24(3): p. 339-347.

9. Matsumoto, $K_{\text {., }}$ et al., Contractile reserve assessed by three-dimensional global circumferential strain as a predictor of cardiovascular events in patients with idiopathic dilated cardiomyopathy. Journal of the American Society of Echocardiography, 2012. 25(12): p. 1299-1308.

\title{
ĐÁNH GIÁ KẾT QUẢ Đİ̂̀U TRỊ SỎI THÂ̂N SAN HÔ BẰNG PHƯƠNG PHÁP TÁN SỎI QUA DA ĐƯờNG HẦM NHỎ TẠI BỆNH VIỆN ĐA KHOA TİNH HẢI DƯO'NG NĂM 2020
}

\section{TÓM TẮT}

Mục tiêu: Đánh giá kết điều trị sỏi thân san hô bằng phương pháp tán sỏi thận qua da đường hầm nhỏ tai Bênh viên Đa khoa tỉnh Hải Dương năm 2020. Phương pháp: Nghiên cứu mô tả, cắt ngang 52 bệnh nhân sỏi thân san hô được điều trị bằng tán sỏi nôi soi qua da đường hầm nhỏ tại bệnh viện đa khoa tỉnh Hải Dương. Kết quả: Tuổi trung bình: $54,9 \pm 11,9$ tuổi; Kích thước sỏi trung bình trên cắt lớp vi tính là $28,1 \pm$ $5,6 \mathrm{~mm}$; Số lượng sỏi: $69,2 \%$ có 1 viên, $7,7 \%$ có 2 viên và $23,1 \%$ có từ 3 viên trở lên; Phân loại sỏi: Sỏi san hô toàn phần $2 / 52$ bệnh nhân, sỏi san hô bán phần 50/52 bệnh nhân (chiếm 96,2\%); Số lần chọc dò: $84,6 \% 1$ lần chọc, $11,5 \% 2$ lấn chọc và 3,8\% 3 lần chọc dò; Số đường hâm: 1 đường hầm 37/52 bệnh nhân (chiếm $71,2 \%$ ), 2 đường hầm 15/52 bệnh nhân (chiếm 28,8\%); Thời gian chọc dò: 13,31 $\pm 6,14$ phút; Tỷ lệ biến chứng sau phẫu thuật là 13/52 bệnh nhân (chiểm 25,0\%); Tỷ lệ sạch sỏi sau 3 ngày là: $67,3 \%$, sau 1 tháng là $80,8 \%$; Kết quả chung sau phấu thuât: Tốt $67,3 \%$, trung bình $30,8 \%$, xấu 1,9\%. Kết luận: Điều trị sỏi thận san hô bằng phương pháp tán sỏi nồi soi qua da tại bệnh viện Đa khoa tỉnh Hải Dương là phương pháp an toàn, hiệu quả với tỷ lệ sạch sỏi cao và tai biến biến chứng thấp.

\section{SUMMARY}

EVALUATE THE RESULT OF TREATMENT OF CORAL KIDNEY STONE BY MINI PERCUTANEOUS NEPHROLITHOTOMY TREATMENT AT

HAI DUONG GENERAL HOSPITAL IN 2020

Objective: To evaluate the result of treatment of coral kidney stone by mini percutaneous nephrolithotomy at Hai Duong General Hospital in 2020. Methods: Descriptive cross - sectional study of 52 patients with coral kidney stone undergone treatment treated with mini percutaneous

*Trường cao đẳng y tế Hà Nội

**BV đa khoa tỉnh Hải Dương

Chịu trách nhiệm chính: Nguyễn Minh An

Email: Dr minhan413@yahoo.com

Ngày nhận bài: 9.4.2021

Ngày phản biên khoa hoc: 27.5.2021

Ngày duyệt bài: 9.6.2021

\section{Nguyễn Minh An*, Đỗ Hải Hùng**}

nephrolithotomy at Hai Duong General Hospital in 2020. Results: The mean age was $54.9 \pm 11.9$ years old; The mean stone size on computed tomography was $28.1 \pm 5.6 \mathrm{~mm}$; Number of stones: 1 stone was $69.2 \%, 2$ stones was $7.7 \%$ and 3 or more stones was $23.1 \%$; Classification of stones: coral stones with $2 / 52$ patients, partial coral stones with $50 / 52$ patients $(96.2 \%)$; Number of punctures: 1 time was $84.6 \%, 2$ times was $11.5 \%$ and 3 times was $3.8 \%$; Number of tunnels: 1 tunnel with 37/52 patients (71.2\%), 2 tunnels with $15 / 52$ patients $(28.8 \%)$; Probe time: $13.31 \pm 6.14$ minutes; The rate of complications after surgery was $25 \%$ with $13 / 52$ patients; The rate of stone removal after 3 days was: $67.3 \%$, after 1 month was $80.8 \%$; Overall outcome after surgery: Good was $67.3 \%$, average was $30.8 \%$, bad was $1.9 \%$. Conclusion: Treatment of coral kidney stones by mini percutaneous nephrolithotomy at Hai Duong General Hospital is safe and effective with high stone clearance rate and less complication.

\section{I. ĐĂT VẤN ĐỀ}

Sỏi tiết niệu là bệnh lý thường gặp ở nước ta và nhiêu nước trên thế giới [1].

Trong các loại sỏi tiết niệu thì sỏi thận san hô là nguy hiểm nhất và khó điều trị nhất, do đặc điểm về hình thái, sinh bệnh học và những biển chứng. Sỏi thận được gọi là sỏi thận san hô khi sỏi bể thận có nhánh vào trong các đài thận. Sỏi thận san hô chiếm $25,4 \%$ sỏi thận, có thể gây ra các biến chứng như viêm nhiễm, suy giảm hoặc mất chức năng thận.

Năm 2016 tại bệnh viện Đa khoa tỉnh Hải Dương triển khai phương pháp tán sỏi thân qua da bằng đường hầm nhỏ dưới hướng dấn của siêu âm, kích cỡ ống nong và Amplatz là $18 \mathrm{fr}$ đã mang lại kết quả nhất định. Tuy nhiên chưa có nghiên cứu nào về kết quả điều trị sỏi thận san hô bằng phương pháp tán sỏi thận qua da đường hầm nhỏ, qua đó chúng tôi thực hiện đề tài: "Đánh giá kết quả điều trị sỏi thận san hô bằng tán sỏi qua da đường hầm nhỏ tại Bệnh viện Đa khoa Tỉnh Hải Dương năm 2020". 


\section{II. ĐỐI TƯợNG VÀ PHƯƠNG PHÁP NGHIÊN CỨU}

2.1 Đối tượng nghiên cứu. Gồm 52 bệnh nhân được chẩn đoán xác định là sỏi thận san hô được điều trị tán sỏi thận qua da đường hầm nhỏ với năng lượng Holmium Laser tại khoa phẫu thuật Tiết niệu - Nam học, Bệnh viện Đa khoa tỉnh Hải Dương trong thời gian từ tháng 01 năm 2017 đến tháng 08 năm 2020.

\section{Tiêu chuẩn lựa chọn bệnh nhân}

- Bênh nhân được chẩn đoán là sỏi thận san hô (theo tiêu chuẩn của Rassweiler J.J [3]) và theo phân loại theo Moores W.K., Boyce P.J. (1976) [3],

- Bênh nhân được điều trị bằng phương pháp tán sỏi thận qua da đường hầm nhỏ với năng lượng Holmium Laser.

- Hồ sơ bệnh án đầy đủ thông tin, hợp lệ

Tiêu chuẩn loại trừ - Bệnh nhân đang có nhiễm khuẩn tiết niệu nặng

- Bệnh nhân bị đái tháo đường chưa điều trị ổn định

- Bệnh nhân có rối loạn đông máu

- Bềnh nhân có thai

- Bệnh nhân có phình động mạch chủ bụng, phình - hẹp động mạch thận

- Bệnh nhẩn có dị tật hệ tiết niệu: thận lạc chỗ, thận móng ngựa.

- Bệnh nhân có chít hẹp niệu quản, hẹp khúc nối bể thận niệu quản

- Hồ sớ bệnh án thiếu thông tin

\subsection{Phương pháp nghiên cứu}

Thiết kế nghiên cứu. Nghiên cứu mô tả cắt ngang, không đối chứng

Cỡ mẫu nghiên cứu. Cỡ mẫu nghiên cứu được xác định theo phương pháp thuận tiện, tất cả các bệnh nhân đảm bảo đủ các tiêu chuẩn nghiên cứu trong thời gian nghiên cứu.

Địa điểm nghiên cứu. Nghiên cứu được tiến hành tại khoa phẫu thuật Tiết niệu - Nam học, Bệnh viện Đa khoa tỉnh Hải Dương

\section{Phương tiện nghiên cứu}

- Nguồn sáng: Nguồn sáng lạnh Xenon 300W.

- Hệ thống camera: Hệ màu PAL độ phân giải trung tâm 450 dòng. Chức năng zoom tiêu cự 25 đến $50 \mathrm{~mm}$.

- Monitor: Chuyên dùng cho phẫu thuật nội soi, hệ màu PAL - NTSC độ phân giải cao đạt trên 600 dòng.

- Máy siêu âm Philips đầu dò 3,5MW.

- Máy bơm nước Senda QB-1.

- Ống kính bán cứng của Karl Storz cõ 13,5 F.

- Kim chọc dò: Kim chọc động mạch Dosantos $18 \mathrm{G} \times 220 \mathrm{~mm}$
- Dụng cụ nong: Bộ nong nhựa (8-18fr) đầu nhọn tù dần theo độ lớn của thước

- Ống nhựa Amplatz kích thước 18 Fr.

- Máy tán sỏi Laser công suất 100W.

Các chỉ tiêu nghiên cứu

- Thời gian chọc dò (tính từ lúc rạch da đến lúc đặt amplatz vào bể thận thành công).

- Thời gian tán sỏi (tính từ lúc tiếp cận sỏi phát tia Lazer tán vụn sỏi và hút, gắp sỏi ).

- Số lần phải chọc dò trên mổi bệnh nhân.

- Các tai biến trong phẫu thuật:

+ Thất bại không tiến hành được tán sỏi

+ Chọc dò nong tạo đường hầm lạc đường, thủng rách bể thânn, cổ đài, vách đài, nhu mô trong quá trình phầu thuật.

+ Tụ dịch, tụ máu hố thận, thủng rách tràn dịch tràn máu tràn khí màng phổi.

+ Chảy máu trong phẫu thuật phải dừng hoặc chuyển phương pháp phẫu thuật, tụt ông Amplatz, dây dẫn...

+ Thất bại chuyển mổ mở số ca chuyển mổ mở.

* Kết quả sớm sau phấu thuật

Sạch sỏi: Trên phim Xquang hệ tiết niệu không chuẩn bị không còn sỏi.

Còn các mảnh sỏi nhỏ: Trên phim Xquang chỉ có các mảnh sỏi $<4 \mathrm{~mm}$. Theo Yang Liu, những mảnh sỏi có kích thước $<4 \mathrm{~mm}$ được xem là không có ý nghĩa trên lâm sàng do những mảnh sỏi này có thể được đào thải ra ngoài theo nước tiểu.

- Biến chứng trong và sau mổ: Các biến chứng trong và sau mổ trong nghiên cứu của chúng tôi sẽ được phân loại theo Clavien Dindo. Theo phân loại này biến chứng được chia làm 5 độ [4]:

- Kết quả chung sau phẫu thuật: Theo tiêu chuẩn từ nghiên cứu của PGS Hoàng Long năm 2017 [5], được chia các mức

+ Tốt: Tán vụn và sạch sỏi; Không có tổn thương đài bể thận; Không có biến chứng trong và sau phẫu thuật; Xét nghiệm công thức máu và sinh hóa máu sau mổ trong giới hạn bình thường.

+ Trung bình: Tán vụn và sạch sỏi: Còn sỏi có đường kính > 3mm; Có tổn thương đài bể thận nhưng không cần can thiệp; Có chảy máu nhưng không cần truyền máu; Xét nghiệm công thức máu, sinh hóa máu các chỉ số trong giới hạn cho phép.

+ Xấu: Không tán được sỏi; Chảy máu nhiều phải chuyển mổ mở; Tổn thương tạng; Có các biến chứng nặng: tràn dịch màng bụng, tràn dịch màng phổi, ngộ độc nước; Xét nghiệm sinh hóa máu, công thức máu có thay đổi lớn gây nguy hiểm cho bệnh nhân, phải truyền máu; Tử vong. 


\section{KẾT QUẢ NGHIÊN CứU}

Từ tháng $1 / 2017$ đến tháng $8 / 2020$ có 52 bệnh nhân sỏi thận san hô được điều trị bằng phương pháp tán sỏi thận qua da đường hầm nhỏ không với năng lượng Holmium Laser tại khoa phẫu thuật Tiết niệu - Nam học, Bệnh viện Đa khoa tỉnh Hải Dương

\section{1. Đặc điểm chung của đối tượng nghiên cứu}

- Tuổi trung bình của bênh nhân là $54,9 \pm$ 11,9 tuổi thấp nhất của bệnh nhân là 30 tuổi, cao nhất là 80 tuổi.

- Số lượng bệnh nhân nam là 31/52 bệnh nhân chiếm $59,6 \%$, nữ $21 / 52$ bệnh nhân chiếm 40,4\%. Tỷ lệ Nam/Nữ là 1,73/1.

-Tiền sử điều trị ngoại khoa tiết niệu: có $9 / 52$ bệnh nhân đã có tiền sử điều trị ngoại khoa sỏi tiết niệu (chiếm 17,3\%) trong đó có $7 / 52$ bệnh nhân đã có tiền sử phẫu thuật mở (chiếm $13,5 \%$ ) và có $2 / 52$ bệnh nhân đã có tiền sử tán sỏi qua da (chiếm 3,8\%).

- Kích thước trung bình của sỏi trên chẩn đoán hình ảnh là $28,1 \pm 5,6 \mathrm{~mm}$, trong đó kích thước lớn nhất của sỏi là $39 \mathrm{~mm}$ và nhỏ nhất là $17 \mathrm{~mm}$. Nhóm sỏi có kích thước từ $2-3 \mathrm{~cm}$ chiếm tỷ lệ 53,8\%.

- Số lượng sỏi trên chẩn đoán hình ảnh: có 36/52 bệnh nhân (chiếm 69,2\%) chỉ có 1 viên sỏi, có $16 / 52$ bệnh nhân (chiếm 30,8\%) có từ hai viên sỏi trở lên.

- Phân loại hình thái sỏi: có 2 bệnh nhân sỏi san hô toàn phần và $50 / 52$ bệnh nhẩn sỏi san hô bán phần (chiếm 96,2\%)

2.2. Đánh giá kêt quả tán sỏi qua da điều trị sỏi san hô

- Số lần chọc dò vào bể thân: có 84,6\% bênh nhân chỉ cân 1 lần chọc dò, 2 lần chọc dò là $11,5 \%$ và $3,8 \%$ số bệnh nhân cần 3 lần chọc dò

- Số đường hầm vào thận: có $37 / 52$ bệnh nhân sử dụng 1 đường hầm (chiếm $71,2 \%$ ), có $15 / 52$ bệnh nhân có 2 đường hầm trong quá trình tán sỏi (chiếm $28,8 \%$ )

- Thời gian chọc dò trung bình là $12,3 \pm 6,14$ phút, dài nhất là 30 phút, ngắn nhất là 5 phút.

- Thời gian tán sỏi trung bình là $57,9 \pm 17,0$ phút, ngắn nhất là 35 phút, dài nhất là 100 phút.

Bảng 1. Tai biến, biến chứng phẫu thuật. \begin{tabular}{|l|l|l|}
\hline Tai biến, biến chứng & Số lượng Tỷ lệ (\%)
\end{tabular}

\begin{tabular}{|c|c|c|}
\hline Chảy máu & 7 & 13,5 \\
\hline Sốt & 5 & 9,6 \\
\hline Mố + đặt lại J] & 1 & 1,9 \\
\hline Tổng & $\mathbf{1 3}$ & $\mathbf{2 5 , 0}$ \\
\hline
\end{tabular}

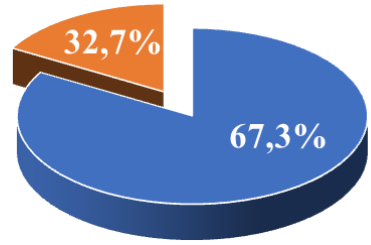

- Sạch sỏi - Còn các mảnh sỏi nhỏ

Biểu đồ 1. Tỷ lệ sạch sỏi sau mồ

Nhận xét: Kết quá nghiên cứu cho thấy có 35/52 bênh nhân (chiếm 67,3\%) sach sỏi sau mổ. Có $17 / 52$ bệnh nhân còn các mảnh sỏi nhỏ (chiếm 32,7\%)

Bảng 2. Kêt quả chung sau phẫu thuât

\begin{tabular}{|c|c|c|}
\hline Kết quả & Số lượng & Tỷ lệ (\%) \\
\hline Tốt & 35 & 67,3 \\
\hline Trung bình & 16 & 30,8 \\
\hline Xấu & 1 & 1,9 \\
\hline Tống & $\mathbf{5 2}$ & $\mathbf{1 0 0}$ \\
\hline
\end{tabular}

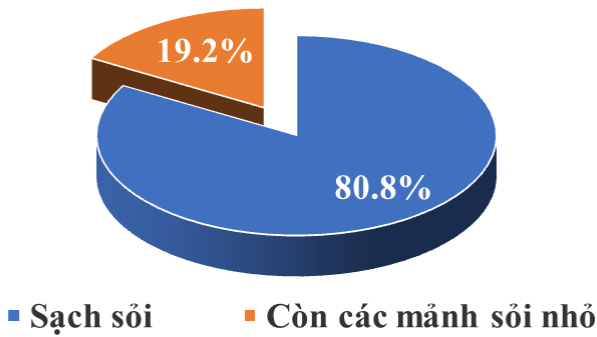

Biểu đồ 2. Tỷ lệ sạch sỏi sau mổ 1 tháng

Nhận xét: Kết quả nghiên cứu cho thây có 42/52 bệnh nhân (chiếm $80,8 \%$ ) sạch sỏi sau mổ. Có $10 / 52$ bệnh nhân còn các mảnh sỏi nhỏ (chiếm 19,2\%)

\section{BÀN LUÂNN}

3.1. Số lượng đường hâm vào thận. Trong tán sỏi nội soi qua da, số đường hầm vào thận tỉ lệ thuận với tî lệ hết sỏi, nhưng thật không may là số lượng biến chứng sẽ tăng lên. Các tác giả thường chủ trương giảm tối đa tỉ lệ biến chứng tuy nhiên vẫn tăng tî lệ hết sỏi dựa vào việc giảm tối đa số đường hầm vào thận đồng thời mở rộng chỉ định tán sỏi ngoài cơ thể phối hợp [1], [2].

Trong nghiên cứu này của chúng tôi, tỷ lệ bệnh nhân có 1 đường hầm vào thận là $37 / 52$ bệnh nhân (chiếm $71,2 \%$ ), có $15 / 52$ bệnh nhân có 2 đường hầm vào thân (chiếm $28,8 \%$ ).

3.2. Thời gian phấu thuật. Thời gian phẫu thuật đóng vai trò rất quan trọng để đánh giá ưu điểm của một phương pháp phẫu thuật. Thời gian phẫu thuật ngắn giúp giảm những tai biến 
về phẫu thuật cũng như tai biến về gây mê hồi sức, giảm chi phí cho người bệnh. Kết quả nghiên cứu của chúng tôi cho thấy, thời gian chọc dò trung bình là $12,3 \pm 6,14$ phút, dài nhất là 30 phút, ngắn nhất là 5 phút. Thời gian tán sỏi trung bình là $57,94 \pm 17,0$ phút, ngắn nhất là 35 phút, dài nhất là 100 phút. Thời gian phẫu thuật trung bình là $82,46 \pm 21,84$ phút, ngắn nhất là 42 phút, dài nhất là 135 phút.

3.3. Tai biến trong tán sỏi và biến chứng sớm sau tán sỏi. Trong nghiên cứu này của chúng tôi, tổng tỷ lệ biến chứng là $13 / 52$ bệnh nhân (chiếm 25,0\%) trong đó có 5 bệnh nhân (chiếm 9,6\%) sau mổ xuất hiện sốt, có 7 bệnh nhân (chiếm 13,5\%) có chảy máu thứ phát sau mổ, biểu hiện bằng nước tiểu qua sonde niệu đạo có màu đỏ, tuy nhiên trường hợp này không cần phải can thiệp gì, bệnh nhân được hướng dẫn nằm nghỉ tai giường và nước tiểu trong trở lại sau 2 ngày điều trị và có 1 bệnh nhân chuyển mổ mở (chiếm 1,92\%)

Theo Trương Phạm Ngọc Đăng [1], Kết quả nghiên cứu cho thấy có 3 trường hợp chảy máu phải ngưng phẫu thuật chiếm $8,1 \%$, trong đó 2 trường hợp phải truyền máu sau mổ chiếm $5,4 \%$. Các trường hợp này đều có thời gian phẫu thuật khá dài là 120 phút và 135 phút. Bệnh nhân được kẹp thông thận và tháo ra sau 30 phút, không có trường hợp nào phải mổ mở cầm máu. Một yếu tố khác nhằm phản ánh mức độ chảy máu trong phẫu thuật là mức độ sụt giảm $\mathrm{Hgb}$ sau mổ với trị số trung bình trong nghiên cứu là $1,9 \mathrm{~g} / \mathrm{dL} \pm 1,02$. Kết quả nghiên cứu của tác giả cũng ghi nhận có sự tương quan thuận mang ý nghĩa thống kê với $p<0,05$ giữa yếu tố này và thời gian phẫu thuật với $R=0,407$, do $0,3 \leq \mathrm{R} \leq 0,5$ nên mối quan hê này ở mức trung bình. Như vậy, khi thời gian phẫu thuật tăng sẽ làm $\mathrm{Hgb}$ sau mổ bị giảm nhiều hơn.

Theo Ahmed R. [6] Trong nghiên cứu đánh giá kết quả điều trị sỏi san hô bằng tán sỏi nội soi qua da từ năm 1999 đến 2009. Kết quả nghiên cứu cho thấy biến chứng sau phẫu thuật gặp ở 54 bệnh nhân (chiếm 22\%), trong đó có 34 bệnh nhân cần truyền máu (chiếm 14\%).

3.4. Tỷ lệ sạch sỏi sau tán sỏi qua da. Tỷ lệ sạch sỏi là một trong những tiêu chí quan trọng nhất để đánh giá tính hiệu quả của các phương pháp điều trị sỏi thận. Các nghiên cứu trước đây đã chỉ ra rằng tán sỏi qua da qua đường hầm tiêu chuẩn và tán sỏi qua da qua đường hầm nhỏ là những phương pháp điều trị sỏi thận có tỷ lệ sạch sỏi rất cao. Tỷ lệ sạch sỏi được xác định là khi không còn mảnh sỏi hoặc mảnh sỏi $\leq 4$ mm trên chụp C-arm sau mổ kết hợp chụp $X$ quang hệ tiết niệu sau mổ 3 ngày.

Trong nghiên cứu này của chúng tôi, đánh giá kết quả sạch sỏi sau 3 ngày có $35 / 52$ bệnh nhân (chiếm 67,3\%) sạch sỏi sau mổ. Có 17/52 bệnh nhân còn các mảnh sỏi nhỏ (chiếm $32,7 \%)$. Tỷ lệ sạch sỏi sau 1 tháng, kết quả nghiên cứu cho thấy có $42 / 52$ bệnh nhân (chiếm $80,8 \%$ ) sạch sỏi sau mổ. Có 10/52 bệnh nhân còn các mảnh sỏi nhỏ (chiếm 19,2\%).

Theo Nguyễn Hoàng Đức [2], tỷ lệ sạch sỏi chung trong nghiên cứu là $86,5 \%$. Khi nghiên cứu mối liên quan giữa vị trí, hình thái sỏi với tỷ lệ sạch sỏi kết quả nghiên cứu cho thấy tỷ lệ sạch sỏi của sỏi đài giữa là $95,8 \%$, sỏi đài dưới là $93,3 \%$ trong khi đó tỷ lệ này của sỏi san hô là $60 \%$ sự khác biệt có ý nghĩa thông kê với $p=$ 0,001 . Theo nghiên cứu của Võ Phước Khương [7], trong nghiên cứu lấy sỏi thận qua da đường hâm vào từ đài dươi điều trị sỏi thận phức tạp, kết quả nghiên cứu cho thây tỉ lệ sạch sỏi toàn bộ là $82,98 \%$, trong đó tỉ lệ sạch sỏi của nhóm sỏi san hô là $81,5 \%$, nhóm nhiều sỏi là $85,7 \%$ và nhóm có bất thường giải phẫu là $85,8 \%$.

3.5. Kết quả chung sau phẫu thuật. Kết quả chung sau phẫu thuật chúng tôi áp dụng theo tiêu chuẩn từ nghiên cứu của Hoàng Long năm 2017 [5], được chia 3 mức Tốt, Trung bình và Xấu. Kết quả nghiên cứu cho thấy có $35 / 52$ bệnh nhân có kết quả tốt sau phẫu thuật (chiếm $67,3 \%)$, có $16 / 52$ bệnh nhân kết quả trung bình (chiếm 30,7\%) và có 1 bệnh nhân đạt kết quả xấu (chiếm 1,9\%)

Theo Shun Kai Chang [8], trong nghiên cứu 216 bệnh nhân sỏi thận được điều trị bằng phương pháp tán sỏi qua da đường hầm nhỏ. Kết quả cho thấy: tỷ lệ truyền máu sau phẫu thuâat là 1,4\%, Sốt sau phâuu thuât là 10,6\%, nhiểm trùng huyết $1,4 \%$. Tất cả các sỏi đích đều được loại bỏ và tỷ lệ sạch sỏi sau phẫu thuật là $100 \%$. Tác giả kết luận rằng tán sỏi qua da không có dẫn lưu thận là phướng pháp hiệu quả, an toàn, giảm thiểu được các biến chứng khó chịu do ống dẫn lưu thận gây ra.

\section{KẾT LUẬN}

Tán sỏi nội soi qua da đường hầm nhỏ là phương pháp án toàn và hiệu quả trong điều trị sỏi san hô với thời gian tán sỏi trung bình 57,94 $\pm 17,0$ phút. Tỷ lệ biến chứng nhẹ sau phẫu thuật chiếm $25,0 \%$, Tỷ lệ sạch sỏi sau 3 ngày là $67,3 \%$, sau 1 tháng là $80,8 \%$. Kết quả chung sau phẫu thuật: Tốt $67,3 \%$, trung bình $30,8 \%$, xấu $1,9 \%$. 


\section{TÀI LIÊU THAM KHẢO}

1. Trương Phạm Ngọc Đăng, Nguyễn Văn Ân, Nguyễn Ngọc Châu (2015), "Đánh giá hiệu quá của tán sỏi thân qua da bằng siêu âm trong sỏi bán san hô", Y hợ TP. Hồ Chí Minh, tâp 19, số 1,17-23.

2. Nguyễn Hoàng Đức, Nguyển Tậ̂n Cương, Trân Lê Linh Phương (2007), "Phẫu thuật lấy sỏi thân qua da", Ngoai khoa tâp 57, tr. 35-41.

3. Rassweiler J.J, C. Renner And F. Eisenberger (2000). The management of complex renal stones. BJU International (2000), 86, 919-928

4. Pierre A. Clavien, Jeffrey Barkun, Michelle L. de Oliveira (2009), "The Clavien-Dindo Classification of Surgical Complications Five-Year Experience", Annals of Surgery, Volume 250, Number 2, August 2009
5. Hoàng Long và CS (2016), "Kết quả tán sỏi thân qua da bằng holmium laser tai bênh viện đai hoc Y Hà Nội", Y học Việt Nam. 445, tháng 8, số đă̆c biệt, tr. 62-71.

6. Ahmed R. El-Nahas, Ibrahim Eraky, Ahmed A. Shokeir (2012). Percutaneous nephrolithotomy for treating staghorn stones: 10 years of experience of a tertiary-care centre. Arab Journal of Urology 10, 324-329

7. Võ Phước Khương, (2012), "Lây sỏi qua da với đường vào thâan tữ đài dưới trong điêu trị sỏi thân phức tap", Y học TP. Hồ Chí Minh phụ bản số 3, 203-207.

8. Shun-Kai Chang, Ian-Seng Cheong. Pressure compression of the cccess tract for tubeless percutaneous nephrolithotomy. Urol Sci, 30, 19-23.

\section{THỰC TRẠNG VĂN HOÁ AN TOÀN NGƯỜI BÊNHH CỦA NHÂN VIÊN Y TẾ BỆNH VIỆN ĐA KHOA LÂM ĐỒNG II, NĂM 2019}

\section{TÓM TẮT}

Việc xác định thực trạng văn hóa an toàn người bênh giúp cho thức hiên an toàn người bênh tai cớ sở y tế được tốt hơn. Nghiên cứu này được thực hiện vớ muc tiêu mô tả thực trang văn hóa an toàn người bệnhcủa nhân viên y tế bệnh viên II Lâm Đồng, năm 2019. Thiết kế nghiên cứu mô tả cắt ngang, sử dung phương pháp kết hợp định lượng và định tính. Thờ gian thức hiên từ tháng 2 đến tháng 9/2019 tai bênh viện II Lâm Đ̇ồng. Bộ câu hỏi của cơ quan Nghiên cứu y tế và chất lượng Hoa Kỳ đo lường 12 lĩnh vực văn hóa an toàn người bệnh đã được sử dụng cho nghiên cứu định lượng trên 357 nhân viên y tế (NVYT) và tiến hành 8 cuộc phỏng vấn sâu cho nghiên cứu định tính. Kết quả cho thấy: Hầu hết lãnh đạo các khoa phòng quan tâm công tác an toàn người bệnh (ATNB); Đa số NVYT có tinh thần làm viêc nhóm, tự học hỏi và hỗ trơ xử trí các vấn đề ATNB trong khoa; 1/3 NVYT cho rằng khoa phòng mình có vấn đề về ATNB; Công tác phản hồi về những sai sót,tỉ lệ trao đổi cởi mở về ATNB và báo cáo sai sót còn chưa nhiêu; Làm việc nhóm giữa các khoa chưa thuận lợi; 1/2 NVYT lo ngai khi bàn giao chuyển người bệnh khi xảy ra sự cố; xấp Xỉ 50\% NVYT đánh giá khoa phòng minh là an toàn; Chỉ 1/3 NVYT thực hiện báo cáo sự cố. Nghiên cứu khuyến nghi cần xây dựng môi trường làm việc tâp trung vào yếu tố $A T N B$, đặc biệt khuyến khích công tác báo cáo sự cố, tâp trung xây dựng các quy trình phối hợp công tác giữa các khoa phòng. Từ khoá: văn hoá an toàn người bệnh, bệnh viện, nhân viên y tế

${ }^{1}$ Trường Đại học Y tế công cộng

2Bênh viên đa khoa II Lâm Đồng

Chịu trách nhiệm chính: Nguyễn Ngọc Bích

Email: nnb@huph.edu.vn

Ngày nhân bài: 5.4.2021

Ngày phản biên khoa hoc: 25.5.2021

Ngày duyệt bài: 7.6.2021

\section{Nguyễn Ngọc Bích ${ }^{1}$, Huỳnh Ngọc Thành ${ }^{2}$ \\ SUMMARY}

PATIENT SAFETY CULTURE AMONG HEALTH WORKERS OF LAM DONG II HOSPITAL, 2019

Patient safety culture awareness and improvement helps managers to improve the patient safety at the hospital. This study aimed to investigate the situation of patient safety cultute at Lam Dong II hospital in 2019.This cross sectional study was conducted from February to September, 2019 using both quantitative and qualitative methods. The tool was NIH questionnaire including 12 sections on patient safety. 357 health workers participated to the quantitative study and 8 indept interviews were implemented. Results show that almost head of departments of the hospital cared about the patient safety. The majority of health workers was good in team work, self learning and support team members. One third of health workers considered that their departments had patient safety problems. Report on medical problems, open discussion were the issues of patient safety culture of the hospital. Only $50 \%$ of health workers think that their departments were safe for patient and only one third of health workers reported their medical faults. It was recommended that the hospital should encourage their workers to report medical faults and develop procedure for that. Keywords: patient safety culture, health workers, hospital

\section{I. ĐĂT VẤN ĐỀ}

Nguyên tắc quan trong nhất của thực hành y khoa là "Điều đầu tiên không gây tổn hại cho người bệnh - First Do No Harm to patient" đang là điều trăn trở đối với các cơ sở, đơn vị Y tế cũng như người hành nghề khám chữa bênh (KCB).

Ủy ban Chất lượng DVYT thuộc Viện Y khoa Hoa Kỳ đưa ra 6 mục tiêu của một DVYT đảm bảo chất lượng, đó là: "An toàn (Safe), Hiệu quả 